\title{
Mikroalglerde Kuru Madde Miktarı ile İliş̧kili Faktörlerin Doğrudan ve Dolaylı Etkilerinin İncelenmesi
}

\author{
Gökhan Tamer KAYAALP ${ }^{1 *}$, Melis ÇELIK GÜNEY ${ }^{1}$, Burcu AK ${ }^{2}$, Oya IŞIK ${ }^{2}$ \\ ${ }^{1}$ Çukurova Üniversitesi, Ziraat Fakültesi, Zootekni Bölümü, Adana. \\ ${ }^{2}$ Çukurova Üniversitesi, Su Ürünleri Fakültesi, Temel Bilimler Bölümü, Adana.
}

Geliş $\quad: 28.03 .2017$

Kabul : 17.08.2017

Araştırma Makalesi / Research Paper

**Sorumlu yazar: tamer.kayaalp@gmail.com

E-Dergi ISSN: 1308-7517

Özet

Phaeodactylum tricornutum kültürlerinde kuru madde miktarı, klorofil $a$, optik yoğunluk, 1şık şiddeti ve sıcaklık ile doğrudan ya da dolaylı olarak ilişkilidir. Bu çalışmada, kuru maddeyi miktarı ile ilişkili faktörlerden önemli olanı belirlemek için path analizi kullanılmıştır. Analize dahil edilen faktörler optik yoğunluk, klorofil $a$, sıcaklık ve 1şık şiddetidir. \%20 aşılama oranı ile kontrol grubu ve $\% 50$ oranında azotun (N) eksiltildiği grup oluşturulmuştur. Çalışmanın sonucunda, kontrol grubunda kuru madde miktarı tahmininde en yüksek doğrudan etkiye sahip faktör optik yoğunluk, en yüksek dolaylı etkiye sahip faktör ise 1şık şiddeti olarak bulunmuştur. Kuru madde miktarı ile optik yoğunluk ve klorofil $a$ arasındaki ilişki istatistiki olarak önemli bulunmuştur. $\% 50$ oranında azot eksiltilen ortamda ise birden büyük path katsayıs1 bulunmuştur. Sıcaklık ve klorofil $a$ değişkenlerinin ise doğrudan ve dolaylı etkilerinin düşük olduğu gözlemlenmiştir.

Anahtar kelimeler: Phaeodactylum tricornutum, Kuru madde miktarı, Path analizi, Korelasyon Analizi, Regresyon Analizi.

\section{Investigation of Direct and Indirect Effects of Factors Related to Dry Matter in Microalgae}

\begin{abstract}
Amount of dry matter are related directly or indirectly with chlorophyll $a$, optical density, light and temperature in Phaeodactylum tricornutum cultures. In this study, path analysis was used to determine which is important for the factors associated with the amount of dry matter. Optical density, chlorophyll $a$, temperature and light intensity were factors included in analysis. It was occured a control group with a $20 \%$ vaccination rate and a 50\% nitrogen $(\mathrm{N})$ reduced group were constituted. At the end of the study, the highest direct effect on the amount of dry matter in the control group was optical density. The light intensity was determinated as the highest indirect effect. The relationship between the amount of dry matter with optical density and chlorophyll $a$ was found statistically significant. Path coefficient was determinated greater than 1 in the $50 \%$ nitrogen reduced medium. Other variables were observed to have low direct and indirect effects.
\end{abstract}

Keywords: Phaeodactylum tricornutum, Dry matter, Path analysis, Correlation Analysis, Regression Analysis.

\section{GİRIŞ}

Mikroalgler, hücre içinde biriktirdikleri metabolitler (protein, vitamin, antibiyotikler gibi) nedeniyle insanlar tarafından kültüre alınmaktadırlar ve bu sebeple mikroalgal biyoteknolojiye olan ilgi giderek artmaktadır (Becker, 1994). Alg teknolojisinde biyokütle verimliliği başka bir deyişle kuru madde miktarı çok önemlidir. Ticari öneme sahip alg türlerinden biri de Phaeodactylum tricornutum olup yağ içeriğinin yüksekliği ile bilinmektedir (Siron vd., 1989; Ward ve Yongmanitchai, 1991; Fajardo vd., 2007). 
Son yıllarda biodizel üretimi için canlı kaynaklar üzerinde yoğun çalışılmakta ve mikroalgal biyokütle üzerinde çok sayıda araştırma yürütülmektedir. Mikroalgal yağlar gerek yakıt kaynağ1 gerekse besin kaynağı olarak ümit vaat eden bir canlı kaynak olmakla birlikte ekonomik üretimi üzerinde en çok durulan konudur. Mikroalgal yağ üretimi kadar biyokütlesel verimlilik de son derece önemlidir. Algal biyoteknoloji çalışmalarında hücrelerin fizyolojisini etkileyen çevre faktörleri kullanılarak istenen metabolitin daha fazla üretilmesi amaçlanmaktadır. $P$. tricornutum hücrelerinde yağ üretimini teşvik etmek amaciyla besi ortamında azot eksiltilmesinin etkili olduğu araştırmalarla saptanmıştır (Liang vd., 2006). Hücrelerin azot eksikliği karşısında strese girdiği ve yă̆ ürettiği saptanmakla birlikte stres aynı zamanda biyokütlede azalmaya da neden olmaktadır (Sukenik vd., 1991; Kilham vd., 1997; Pruvost vd., 2009; Xin vd., 2010; Slade ve Bauen, 2013). Bir mikroalg kültür işletmesinin verimli ve ekonomik işletilebilmesi biyokütle verimliliği, yağ içeriği ve ekonomik analizin birlikte değerlendirilmesini gerektirmektedir.

Mikroalg kültürlerinde büyümenin belirlenmesi, hücre sayımı, pigment ölçümü, karbon miktarı gibi parametrelerin belirlenmesi ile yapılabildiği gibi, büyük hacimlerdeki kültürlerde kuru madde miktarının belirlenmesi ya da optik yoğunluk ölçümü ile de yapılabilir. Kuru madde miktarının belirlenmesi bir laboratuvar çalışması gerektirir. Kültürden filtre edilerek yoğunlaştırılan yaş mikroalg kütlesi kurutulur ve birim kültür hacmindeki alg kütlesi belirlenir. Monokültürlerde spektrofotometrik olarak hücre yoğunluğuna bağlı 1şık geçirgenliği ile optik okuma yapılarak da alg kültürlerinde büyüme belirlenebilir (Acién Fernández vd., 2003; Richmond, 2004; Griffiths vd., 2011).

Yığın kültürler olarak adlandırılan büyük hacimli mikroalg kültürlerinde kuru madde miktarı ile ilişkili birçok faktör vardır. Bu faktörlerin birbiriyle olan ilişkisi incelendiğinde bazı faktörlerin doğrudan etkiye, bazı faktörlerin ise dolaylı etkiye sahip olduğu görülmektedir. $\mathrm{Bu}$ etkilerin belirlenmesinde korelasyon katsayıları yeterli bilgiyi verememektedir. $\mathrm{Bu}$ nedenle path analizine ihtiyaç duyulmaktadir. Path katsayısı, bağımsız değişkende meydana gelen değişmenin, diğer değişkenlerin hepsini etkiliyken standart sapma cinsinden meydana gelen değişime oranı olarak tanımlanmaktadır (Wright, 1921; Oktay vd., 2012).

Bu çalışmanın amacı, mikroalg Phaeodactylum tricornutum'un iki ayrı besi ortamında, kuru madde miktarını etkileyen çevresel faktörlerden 1 şı ve sıcaklık ile biomas verimliliğini belirlemede kullanılan optik yoğunluk ve klorofil $a$ faktörlerinin doğrudan ve dolaylı etkilerini belirleyerek kuru madde miktarının tahmininde bu faktörlerden hangilerinin üreticiye yardımcı olacağının belirlenmesidir.

\section{MATERYAL ve YÖNTEM}

Çalışmada materyal olarak kullanılan mikroalg Phaeodactylum tricornutum için kontrol grubu olarak oluşturulan kültürde $882 \mu$ molL $^{-1} \mathrm{~N}$ ve N'un $\% 50$ oranında eksiltildiği diğer kültürde $441 \mu \mathrm{molL}^{-1} \mathrm{~N}$ elementi olacak şekilde iki ayrı besi ortamı hazırlanmıştır (Ak, 2013). Kuru madde miktarını belirlemede kullanılan optik yoğunluk, klorofil $a$ değerleri ile sıcaklık ve 1şık şiddeti çevresel faktörleri kullanılarak doğrudan ve dolaylı etkiler incelenmiştir. Analiz için SPSS $22 \mathrm{~V}$. paket programı kullanılmıştır.

Analize dahil edilen bağımlı ve bağımsız değişkenler aşağıdaki gibidir.

Y : Kuru madde miktarı

$\mathrm{X}_{1}$ : Optik yoğunluk

$\mathrm{X}_{2}$ : Klorofil a 
$\mathrm{X}_{3}$ : Sicaklik

$\mathrm{X}_{4}$ : Işı1k şiddeti

Kuru madde miktarının belirlenmesi için, $0,45 \mu$ göz açıklığındaki filtre kağıtları, süzme düzeneği ve bir su trombu kullanarak oluşturulan vakumla hücreler ortamdan ayrılarak yoğunlaştırılmıştır. Filtre kağıtları 105 derecede tutulup desikatörde soğutulduktan sonra hassas terazide tartımları yapılmıştır (Boussiba vd., 1992).

Optik yoğunluk, Phaeodactylum tricornutum için $625 \mathrm{~nm}$ (Shimadzu, UV mini 1240) dalga boyunca visible spektrofotometre ile değerlendirilmiştir (Acièn Fernàndez vd., 2003).

Klorofil $a$ analizi için, 5 mL'lik örnek su trombu yardımıyla filtre kağıdından süzülmüş ve deney tüplerine konulmuştur. Üzerine aseton eklenmiştir. Asiditenin artması ve pigmentin zarar görmemesi için $\mathrm{MgCO}_{3}$ eklenmiştir. Ağıları kapatılarak buzdolabında 24 saat bırakılmış ve ekstraksiyon süresi sonunda üstteki berrak kısım alınarak visible spektrofotometrede (Shimadzu, UV mini 1240) 630, 645, 665, $750 \mathrm{~nm}$ 'de absorbsiyon değerleri ölçülmüştür. $750 \mathrm{~nm}$ 'de okunan değerler bulanıklık düzeltme faktörü olarak kullanılmıştır ve bu değerler diğer dalga boylarında okunan değerlerden çıkarılarak klorofil a konsantrasyonları ilgili eşitlikten hesaplanmıştır (Parsons ve Strickland, 1963).

Kuru madde miktarını etkileyen diğer faktörler ise sıcaklık ve 1şı şiddetidir. Phaeodactylum tricornutum türü $20^{\circ} \mathrm{C}$ sicaklıkta, 7 farklı 1şı şiddetine $(100,500,1000$, 3000, 5000, 8000, 10000 lux) maruz bırakıldı̆̆ında 10.000 lux 1şık şiddetinde maksimum gelişme göstermiştir ve maksimum büyüme h1zı $\mu$ max=2,0637 $\pm 0,16$ çiftlenme/gün'dür (Madenci, 2012).

Kuru madde miktarı ile ilişkili faktörler arasındaki toplam korelasyonun doğrudan ve dolaylı etkilere ayrılması aşağıdaki eşitlikteki gibidir.

$$
\begin{aligned}
& \mathrm{r}\left(\mathrm{X}_{1}, \mathrm{Y}\right)=\mathrm{P}_{\mathrm{YX}_{1}}+\mathrm{r}_{\mathrm{X}_{1} \mathrm{X}_{2}} \mathrm{P}_{\mathrm{YX}_{2}}+\mathrm{r}_{\mathrm{X}_{1} \mathrm{X}_{3}} \mathrm{P}_{\mathrm{YX}_{3}}+\mathrm{r}_{\mathrm{X}_{1} \mathrm{X}_{4}} \mathrm{P}_{\mathrm{YX}_{4}} \\
& r\left(X_{2}, Y\right)=r_{X_{1} X_{2}} P_{Y_{1}}+P_{Y X_{2}}+r_{X_{2} X_{3}} P_{Y_{X}}+r_{X_{2} X_{4}} P_{Y_{X}} \text { (1) }
\end{aligned}
$$

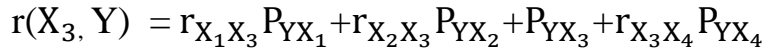

$$
\begin{aligned}
& \mathrm{r}\left(\mathrm{X}_{4}, \mathrm{Y}\right)=\mathrm{r}_{\mathrm{X}_{1} \mathrm{X}_{4}} \mathrm{P}_{\mathrm{YX}_{1}}+\mathrm{r}_{\mathrm{X}_{2} \mathrm{X}_{4}} \mathrm{P}_{\mathrm{YX}_{2}}+\mathrm{r}_{\mathrm{X}_{3} \mathrm{X}_{4}} \mathrm{P}_{\mathrm{YX}_{3}}+\mathrm{P}_{\mathrm{YX}_{4}}
\end{aligned}
$$

Yukarıdaki eşitlikte belirtilen $\mathrm{P}_{\mathrm{YX}}$, i. bağımsız değişkenin $\mathrm{Y}$ bağımlı değişken üzerindeki doğrudan etkiyi, $r_{X_{i} X_{j}}$, i. ve j. bağımsız değişkenler arasındaki korelasyon katsayısını, $r_{X_{i} X_{j}} P_{Y X_{j}}$ ise i. bağımsız değişkenin $j$. bağımsız değişken üzerindeki dolaylı etkiyi göstermektedir (Mendeş vd., 2005).

(1) nolu eşitlik matris forma dönüştürülerek aşağıdaki gibi yazılır (Sıralı ve Kayaalp, 1995).

$$
\left[\begin{array}{l}
\mathrm{P}_{\mathrm{YX}_{1}} \\
\mathrm{P}_{\mathrm{YX}_{2}} \\
\mathrm{P}_{\mathrm{YX}_{3}} \\
\mathrm{P}_{\mathrm{YX}_{4}}
\end{array}\right]=\left[\begin{array}{llll}
\mathrm{r}_{\mathrm{X}_{1} \mathrm{X}_{1}} & \mathrm{r}_{\mathrm{X}_{1} \mathrm{X}_{2}} & \mathrm{r}_{\mathrm{X}_{1} \mathrm{X}_{3}} & \mathrm{r}_{\mathrm{X}_{1} \mathrm{X}_{4}} \\
\mathrm{r}_{\mathrm{X}_{2} \mathrm{X}_{1}} & \mathrm{r}_{\mathrm{X}_{2} \mathrm{X}_{2}} & \mathrm{r}_{\mathrm{X}_{2} \mathrm{X}_{3}} & \mathrm{r}_{\mathrm{X}_{2} \mathrm{X}_{4}} \\
\mathrm{r}_{\mathrm{X}_{3} \mathrm{X}_{1}} & \mathrm{r}_{\mathrm{X}_{3} \mathrm{X}_{2}} & \mathrm{r}_{\mathrm{X}_{3} \mathrm{X}_{3}} & \mathrm{r}_{\mathrm{X}_{3} \mathrm{X}_{4}} \\
\mathrm{r}_{\mathrm{X}_{4} \mathrm{X}_{1}} & \mathrm{r}_{\mathrm{X}_{4} \mathrm{X}_{2}} & \mathrm{r}_{\mathrm{X}_{4} \mathrm{X}_{3}} & \mathrm{r}_{\mathrm{X}_{4} \mathrm{X}_{4}}
\end{array}\right]^{-1} \cdot\left[\begin{array}{c}
\mathrm{r}\left(\mathrm{X}_{1}, \mathrm{Y}\right) \\
\mathrm{r}\left(\mathrm{X}_{2}, \mathrm{Y}\right) \\
\mathrm{r}\left(\mathrm{X}_{3}, \mathrm{Y}\right) \\
\mathrm{r}\left(\mathrm{X}_{4}, \mathrm{Y}\right)
\end{array}\right]
$$

Yukarıdaki matris çözümlenerek doğrudan etkiler bulunmaktadır. Doğrudan etkiler, path katsayılarıdır. Doğrudan ve dolaylı etkilerin toplamı, toplam etki olarak ifade edilir. Toplam etki aynı zamanda korelasyon katsayısıdır. 
Belirtme katsayısı $\left(\mathrm{R}^{2}\right)$ aşağıdaki eşitlikten bulunur (Düzgüneş vd., 1976).

$\mathrm{R}^{2}=\mathrm{P}_{\mathrm{YX}_{1}}{ }^{2}+\mathrm{P}_{\mathrm{YX}_{2}}{ }^{2}+\mathrm{P}_{\mathrm{YX}_{3}}{ }^{2}+\mathrm{P}_{\mathrm{YX}_{4}}{ }^{2}+2 \mathrm{r}_{\mathrm{X}_{1} \mathrm{X}_{2}} \mathrm{P}_{\mathrm{YX}_{1}} \mathrm{P}_{\mathrm{YX}_{2}}+2 \mathrm{r}_{\mathrm{X}_{1} \mathrm{X}_{3}} \mathrm{P}_{\mathrm{YX}_{1}} \mathrm{P}_{\mathrm{YX}_{3}}+2 \mathrm{r}_{\mathrm{X}_{1} \mathrm{X}_{4}} \mathrm{P}_{\mathrm{YX}_{1}} \mathrm{P}_{\mathrm{YX}_{4}}+2$ $\mathrm{r}_{\mathrm{X}_{2} \mathrm{X}_{3}} \mathrm{P}_{\mathrm{YX}_{2}} \mathrm{P}_{\mathrm{YX}_{3}}+2 \mathrm{r}_{\mathrm{X}_{2} \mathrm{X}_{4}} \mathrm{P}_{\mathrm{YX}_{2}} \mathrm{P}_{\mathrm{YX}_{4}}+2 \mathrm{r}_{\mathrm{X}_{3} \mathrm{X}_{4}} \mathrm{P}_{\mathrm{YX}_{3}} \mathrm{P}_{\mathrm{YX}_{4}}$ (3)

Korelasyon katsayısı -1 ile 1 arasında değişmektedir. Ancak path katsayısı bu sayıların dışına çıkabilmektedir. Eğer path katsayısı 1'den büyük çıkarsa sistemde dengeleyici mekanizmanın (negatif etkinin) olmasindandır ( $\mathrm{Li}, 1975)$. Bu path katsay1s1 anlamlı değildir ve göz ardı edilmelidir. Bu nedenle belirtme katsayısının da yorumlanması zorlaşmaktadır. $\mathrm{Bu}$ gibi durumlar path analizinin dezavantajları arasındadır (Kaşıkçı, 2000; Daşdă̆ vd., 2006).

Bağımsız değişkenler arasındaki korelasyon nedeniyle ortaya çıkan çoklu bağlantı problemi varlığının kontrol edilmesi gerekmektedir. Kontrol yöntemlerden biri varyans büyültme faktörü (VIF) ve tolerans (T) değerlerinin belirlenmesidir (Öztürk, 2014). VIF değeri 10'dan büyük olması veya T değerlerinin 0,10 'dan küçük olması durumunda çoklu bağlantı sorununun varlığ 1 kabul edilmektedir (Webster, 1995).

\section{BULGULAR}

Öncelikle bağımsız değişkenler arasında çoklu bağlantı probleminin kontrolü yapılmıştır. Tüm bağımsız değişkenlerin VIF değerinin 10'dan küçük ve aynı zamanda T değeri 0,10 'dan büyük olduğu gözlemlenmiştir. Bu da çoklu bağlantının olmadığını gösterir. Bu nedenle tüm değişkenler analize dahil edilmiştir.

Kuru madde miktarı (Y) ile ilişkili, optik yoğunluk $\left(\mathrm{X}_{1}\right)$, klorofil a $\left(\mathrm{X}_{2}\right)$, sicaklık $\left(\mathrm{X}_{3}\right)$ ve 1ş1k şiddeti $\left(\mathrm{X}_{4}\right)$ arasındaki korelasyon katsayıları Tablo 1'de verilmiştir.

Tablo 1. En uygun besi ortamında (kontrol grubu) değişkenler arasındaki basit korelasyon katsayıları

\begin{tabular}{clllll}
\hline \hline & $\mathbf{Y}$ & $\mathbf{X}_{\mathbf{1}}$ & $\mathbf{X}_{\mathbf{2}}$ & $\mathbf{X}_{\mathbf{3}}$ & $\mathbf{X}_{\mathbf{4}}$ \\
\hline $\mathbf{Y}$ & 1 & & & & \\
$\mathbf{X}_{\mathbf{1}}$ & $0,966^{* *}$ & 1 & & & \\
$\mathbf{X}_{\mathbf{2}}$ & $0,922^{* *}$ & $0,896^{* *}$ & 1 & & \\
$\mathbf{X}_{\mathbf{3}}$ & $-0,531^{*}$ & $-0,602^{*}$ & $-0,406$ & 1 & \\
$\mathbf{X}_{\mathbf{4}}$ & $-0,863^{* *}$ & $-0,879^{* *}$ & $-0,886^{* *}$ & $0,637 *$ & 1 \\
\hline * $\mathrm{p}<0,05^{* * \mathrm{p}<0,01}$ & & & & &
\end{tabular}

Tablo 1.'den yararlanılarak (1) nolu eşitlikte verilen denklem sistemleri aşağıdaki gibidir.

$$
\begin{aligned}
& 0,966=\mathrm{P}_{\mathrm{YX}_{1}}+0,896 \mathrm{P}_{\mathrm{YX}_{2}}-0,602 \mathrm{P}_{\mathrm{YX}_{3}}-0,879 \mathrm{P}_{\mathrm{YX}_{4}} \\
& 0,922=0,896 \mathrm{P}_{\mathrm{YX}_{1}}+\mathrm{P}_{\mathrm{YX}_{2}}-0,406 \mathrm{P}_{\mathrm{YX}_{3}}+0,886 \mathrm{P}_{\mathrm{YX}_{4}} \\
& -0,531=-0,602 \mathrm{P}_{\mathrm{YX}_{1}}-0,406 \mathrm{P}_{\mathrm{YX}_{2}}+\mathrm{P}_{\mathrm{YX}_{3}}+0,637 \mathrm{P}_{\mathrm{YX}_{4}} \\
& -0,863=-0,879 \mathrm{P}_{\mathrm{YX}_{1}}-0,886 \mathrm{P}_{\mathrm{YX}_{2}}+0,637 \mathrm{P}_{\mathrm{YX}_{3}}+\mathrm{P}_{\mathrm{YX}_{4}}
\end{aligned}
$$

Yukarıdaki eşitliklerde bilinmeyen path katsayılarıdır. $\mathrm{Bu}$ denklem sistemi matris forma dönüştürülerek path katsayıları bulunmuştur. 


$$
\left[\begin{array}{cccc}
1 & 0,896 & -0,602 & -0,879 \\
0,896 & 1 & -0,406 & 0,886 \\
-0,602 & -0,406 & 1 & 0,637 \\
-0,879 & -0,886 & 0,637 & 1
\end{array}\right]^{-1} *\left[\begin{array}{c}
0,966 \\
0,922 \\
-0,531 \\
-0,863
\end{array}\right]=\left[\begin{array}{c}
0,816 \\
0,198 \\
0,036 \\
0,007
\end{array}\right]
$$

$\mathrm{P}_{\mathrm{YX}_{1}}=0,816 \quad \mathrm{P}_{\mathrm{YX}_{2}}=0,198 \quad \mathrm{P}_{\mathrm{YX}_{3}}=0,036 \quad \mathrm{P}_{\mathrm{YX}_{4}}=0,007$

$\mathrm{R}^{2}=0,816^{2}+\ldots+0,007^{2}+2 \times 0,896 \times 0,816 \times 0,198+\ldots+2 \times 0,637 \times 0,036 \times 0,007=0,942$

Kontrol grubunda her değişken için doğrudan ve dolaylı etkiler Tablo 2'de belirtilmiştir.

Tablo 2. Kontrol grubunda kuru madde miktarı ile ilişkili faktörlerin doğrudan ve dolaylı etkileri

\begin{tabular}{lllllll}
\hline \hline Değişkenler & $\begin{array}{l}\text { Doğrudan } \\
\text { etkiler }\end{array}$ & \multicolumn{4}{c}{ Dolaylı etkiler } & Toplam \\
\cline { 3 - 6 } & & $\mathbf{X}_{\mathbf{1}}$ & $\mathbf{X}_{\mathbf{2}}$ & $\mathbf{X}_{\mathbf{3}}$ & $\mathbf{X}_{\mathbf{4}}$ & etki \\
\hline $\mathbf{X}_{\mathbf{1}}$ & 0,816 & - & 0,177 & $-0,021$ & $-0,006$ & 0,966 \\
$\mathbf{X}_{\mathbf{2}}$ & 0,198 & 0,732 & - & $-0,015$ & 0,007 & 0,922 \\
$\mathbf{X}_{\mathbf{3}}$ & 0,036 & $-0,491$ & $-0,081$ & - & 0,0045 & $-0,531$ \\
$\mathbf{X}_{\mathbf{4}}$ & 0,007 & $-0,717$ & $-0,18$ & 0,03 & - & $-0,863$ \\
\hline \hline
\end{tabular}

Tablo 2'de verilen doğrudan etkiler path katsayılarıdır. Dolaylı etkiler ise her bağımsız değişkenin birbirleri üzerine etkisidir. $X_{1}$ değişkeninin dolaylı etkisi aşağıdaki gibi bulunmuştur.

$\mathrm{X}_{1}$ 'in $\mathrm{X}_{2}$ üzerindeki dolaylı etkisi; $\mathrm{P}_{\mathrm{YX}_{2}} \mathrm{r}_{\mathrm{X}_{1} \mathrm{X}_{2}}=0,198 * 0,896=0,177$

$\mathrm{X}_{1}$ 'in $\mathrm{X}_{3}$ üzerindeki dolaylı etkisi; $\mathrm{P}_{\mathrm{YX}_{3}} \mathrm{r}_{\mathrm{X}_{1} \mathrm{X}_{3}=0,036 *(-0,602)=-0,021}$

$\mathrm{X}_{1}$ 'in $\mathrm{X}_{4}$ üzerindeki dolaylı etkisi; $\mathrm{P}_{\mathrm{YX}_{4}} \mathrm{r}_{\mathrm{X}_{1} \mathrm{X}_{4}=0,007 *(-0,879)=-0,006}$

$\mathrm{X}_{1}$ değişkenin bağımsız değiş̧kenler üzerindeki dolaylı etkisi ;

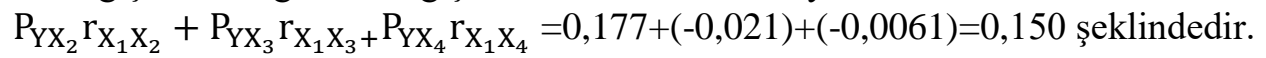

Diğer bağımsız değişkenlerin doğrudan, dolaylı ve toplam etkileri benzer şekilde bulunmuştur.

Phaeodactylum tricornutum, $\% 50 \mathrm{~N}$ eksik besi ortamında kültüre alındıktan sonra kuru madde miktarı ile ilişkili faktörlerin doğrudan ve dolaylı etkileri kontrol grubunda olduğu gibi incelenmiştir.

Tablo 3. \%50 N eksik besi ortamında değişkenler arasındaki basit korelasyon katsayıları

\begin{tabular}{llllll}
\hline \hline & $\mathbf{Y}$ & $\mathbf{X}_{\mathbf{1}}$ & $\mathbf{X}_{\mathbf{2}}$ & $\mathbf{X}_{\mathbf{3}}$ & $\mathbf{X}_{\mathbf{4}}$ \\
\hline $\mathbf{Y}$ & 1 & & & & \\
$\mathbf{X}_{\mathbf{1}}$ & $0,951^{* *}$ & 1 & & & \\
$\mathbf{X}_{\mathbf{2}}$ & $-0,285$ & $-0,357$ & 1 & & \\
$\mathbf{X}_{\mathbf{3}}$ & $-0,308$ & $-0,419$ & $0,855^{* *}$ & 1 & \\
$\mathbf{X}_{\mathbf{4}}$ & $-0,640^{*}$ & $-0,729 * *$ & $0,672^{*}$ & 0,559 & 1 \\
\hline \hline$* \mathrm{p}<0,05$ & & & & \\
$* * \mathrm{p}<0,01$ & & & &
\end{tabular}


Tablo 3 'ten yararlanılarak (1) nolu eşitlikte verilen denklem sistemleri aşağıdaki gibidir.

$$
\begin{aligned}
& 0,951=\mathrm{P}_{\mathrm{YX}_{1}}-0,357 \mathrm{P}_{\mathrm{YX}_{2}}-0,419 \mathrm{P}_{\mathrm{YX}_{3}}-0,729 \mathrm{P}_{\mathrm{YX}_{4}} \\
& -0,285=-0,357 \mathrm{P}_{\mathrm{YX}_{1}}+\mathrm{P}_{\mathrm{YX}_{2}}+0,855 \mathrm{P}_{\mathrm{YX}_{3}}+0,672 \mathrm{P}_{\mathrm{YX}_{4}} \\
& -0,308=-0,419 \mathrm{P}_{\mathrm{YX}_{1}}+0,855 \mathrm{P}_{\mathrm{YX}_{2}}+\mathrm{P}_{\mathrm{YX}_{3}}+0,559 \mathrm{P}_{\mathrm{YX}_{4}} \\
& -0,640=-0,729 \mathrm{P}_{\mathrm{YX}_{1}}+0,672 \mathrm{P}_{\mathrm{YX}_{2}}+0,559 \mathrm{P}_{\mathrm{YX}_{3}}+\mathrm{P}_{\mathrm{YX}_{4}}
\end{aligned}
$$

Path katsayılarını bulmak için denklem sistemi matris forma aşağıdaki şekilde dönüştürülmüştür.

$$
\begin{aligned}
& {\left[\begin{array}{cccc}
1 & -0,357 & -0,419 & -0,729 \\
-0,357 & 1 & 0,855 & 0,672 \\
-0,419 & 0,855 & 1 & 0,559 \\
-0,729 & 0,672 & 0,559 & 1
\end{array}\right]^{-1} *\left[\begin{array}{r}
0,951 \\
-0,285 \\
-0,308 \\
-0,640
\end{array}\right]=\left[\begin{array}{r}
1,098 \\
-0,207 \\
0,235 \\
0,168
\end{array}\right]} \\
& \mathrm{P}_{\mathrm{YX}_{1}}=1,098 \quad \mathrm{P}_{\mathrm{YX}_{2}}=-0,207 \quad \mathrm{P}_{\mathrm{YX}_{3}}=0,235 \quad \mathrm{P}_{\mathrm{YX}_{4}}=0,168
\end{aligned}
$$

\begin{tabular}{|c|c|c|c|c|c|c|}
\hline \multirow[t]{2}{*}{ Değişkenler } & \multirow{2}{*}{$\begin{array}{l}\text { Doğrudan } \\
\text { etkiler }\end{array}$} & \multicolumn{4}{|c|}{ Dolaylı etkiler } & \multirow{2}{*}{$\begin{array}{l}\text { Toplam } \\
\text { etki }\end{array}$} \\
\hline & & $\mathbf{X}_{1}$ & $\mathbf{X}_{2}$ & $\mathbf{X}_{3}$ & $\mathbf{X}_{4}$ & \\
\hline $\mathbf{X}_{1}$ & 1,098 & - & 0,074 & $-0,099$ & $-0,122$ & 0,951 \\
\hline $\mathbf{X}_{2}$ & $-0,207$ & $-0,39$ & - & 0,200 & 0,112 & $-0,285$ \\
\hline $\mathbf{X}_{\mathbf{3}}$ & 0,235 & $-0,460$ & $-0,176$ & - & 0,093 & $-0,308$ \\
\hline$X_{4}$ & 0,168 & $-0,800$ & $-0,139$ & 0,131 & - & $-0,640$ \\
\hline
\end{tabular}

Kontrol grubunda olduğu gibi \%50 N eksiltilen ortamda hesaplanan değişkenlerin doğrudan ve dolaylı etkileri Tablo 4'te belirtilmiştir.

Tablo 4. $\% 50$ oranında azot eksiltilen besi ortamında kuru madde miktarı ile ilişkili faktörlerin doğrudan ve dolaylı etkileri

\%50 oranında azot eksiltilen besi ortamında kuru madde miktarı ile ilişkili doğrudan ve tüm dolaylı etkiler kontrol grubunda açıklandığı gibi bulunmuştur.

\section{TARTIŞMA ve SONUÇ}

Endüstriyel ölçekli ototrofik mikroalgal kültürlerin sürdürülebilirliği, dişarı ortamda çevresel faktörlerden 1 şık ve sıcaklık ile doğrudan ilişkilidir. Ticari değeri olan mikroalgal metabolitlerin ekonomik üretimi de doğrudan bu faktörlerden etkilenmektedir. Phaeodactylum tricornutum yağ üretimi ile bilinen bir mikroalg türü olup azot eksikliği stres faktörü koşulunda yă̆ üretmektedir. Phaeodactylum tricornutum ile yürütülen bir çalışmada kontrol grubunda lipid oranı \%16,93, kuru madde miktarı 1,036 g/l olarak saptanırken azot eksikliği uygulanan kültürlerde lipid oranı $\% 35.04$ ve kuru madde miktarı 0,980 g/l olarak belirlenmiştir (Ak vd., 2015). Büyük ölçekli mikroalg ticari kültürlerinde büyümenin ve biyomas verimliliğinin sürekliliğinin sabitlenmesi etkin bir kültür için son derece önemlidir. Ototorof mikroalg kültürlerinde 1 şık ve sıcaklık biyomas verimliliğini doğrudan etkilemektedir. Korofil $a$ ve optik yoğunluk değerleri mikroalg kültürlerinde büyümenin belirlenmesinde kullanılan parametrelerdir. 
Çalışmada, Phaeodactylum tricornutum kültürü için en uygun besi ortamında, kuru madde miktarı ile ilişkili doğrudan etkiye sahip faktör, aynı zamanda en yüksek path katsayısına sahip faktör optik yoğunluk olarak bulunmuştur. Aynı zamanda kuru madde miktarı ile optik yoğunluk arasında en yüksek korelasyonun bulunması $(r=0,966)$ ve bu korelasyonun istatistiki olarak önemli bulunması da $(\mathrm{p}<0,01)$ bunun bir göstergesidir (Tablo 1).

En yüksek dolaylı etkiye sahip faktör 1 şık şiddetidir. Işık şiddetinin, optik yoğunluk ile birlikte yapmış olduğu dolaylı etki en fazladır (Tablo 2). Kuru madde miktarı ile 1şık şiddeti arasında negatif ve güçlü bir ilişki vardır $(\mathrm{r}=-0,863)$. Bu ilişki yüksek olmasına karşın kuru madde miktarına doğrudan değil dolaylı etkiye sahiptir. Kontrol grubunun $\mathrm{R}^{2}$ değeri ise 0,942 olarak bulunmuştur. Tubular fotobiyoreaktörde Phaeodactylum tricornutum dışarı kültüründe aydınlanma profili ve reaktör içindeki ortalama aydınlanma şiddetini tahmin etmek için matematik bir modelin önerildiği bir çalışmada, aydınlanmanın zayıflaması ile biyomas konsantrasyonu arasında amprik bir ilişki önerilmiştir. Önerilen matematik model, dışarı ortamda tubular fotobiyoreaktörde büyüyen bir kültürde 1şının, spesifik bir noktaya izlediği yolun uzunluğunu tahmin etmeye yardımcı olmak üzere önerilmiştir. Ancak çalışmada, literatürdeki hiçbir modelin mikroalgal kültürde yüksek konsantrasyondaki biyomas ile güneş 1şığındaki azalmayı yeterli düzeyde açıklamadığı ifade edilmekte ve bu nedenle de yeni bir hiperbolik eşitlik önerilmektedir. Önerilen modelin dışarı kültürlerde, yıllık biyomas verimliliği tahmini ve türe ve 1şığa bağlı tüpte çap optimizasyonuna katkı sağlayacağı ifade edilmektedir (Acien Fernandez vd.,1997). Bu çalışmada bulunan en yüksek doğrudan ve dolaylı etkiye sahip faktörler olan optik yoğunluk ve 1 şık şiddeti kullanılarak tubular reaktörde 1 şık yolu ölçüleri girilerek önerilen hiperbolik eşitlik yardımıyla biyomas tahmini yapılabilir.

\%50 oranında $\mathrm{N}$ eksiltilen besi ortamında kuru madde miktarı ile ilişkili doğrudan ve dolaylı etkileri incelediğimizde (Tablo 4), birden büyük path katsayısı gözlemlenmektedir. 1 'den büyük path katsayısı tek olarak anlamlı olmadığ 1 için göz ardı edilmiştir. En yüksek dolaylı etkiye sahip faktör, kontrol grubunda olduğu gibi 1 şı şiddetidir. Yine 1ş1k şiddetinin, optik yoğunluk ile birlikte yapmış olduğu dolaylı etki en fazladır. Path katsayılarından birisi 1'den büyük çıktığı için $\mathrm{R}^{2}$ 'nin yorumlanması zorlaştığından bulunmamiştır.

Yürütülen bir başka çalışmada, dışarı koşullarında, sınırlı 1şık ve fazla 1şık koşullarında Phaeodactylum tricornutum'dan eicosapentaenoic asit (EPA) üretiminin tahmini için bir model geliştirmeye yönelik olmuştur. Çalışma üç aşamada yürütülmüştür; dişarı koşullarında tubular fotobiyoreaktörlerde 1şı̆̆ıı kullanılabilirliği (Acièn Fernàndez vd., 1997), 1şı̆̆a bağlı büyüme ve biyomas verimliliği modellemesi (Acièn Fernàndez vd., 1998), ve son olarak $P$. tricornutum da EPA verimliliğinin modellemesidir. Bu modellemeler, çevresel faktörler ve kültür parametrelerinin tahminine yardımcı olmaktadır ve yıllık EPA verimliliği tahmin edilebilmektedir (Acièn Fernàndez vd., 2000). Acièn Fernàndez vd. (1997) mikroalg tubular fotobiyoreaktörlerde dışarı ortam kültürlerinde yıl boyu biyomas verimliliğini tahmin etmek üzere bir makromodel geliştirmişlerdir. Model, optimum seyreltme oranı ve biyomas verimliliğini belirlemede kullanılabilmektedir.

Sonuç olarak, kuru madde miktarının tahmininde en yüksek doğrudan ve dolaylı etki sırasıyla optik yoğunluk ve 1şı şiddeti olarak bulunmuştur. $\mathrm{Bu}$ nedenle alg üretiminde biyokütle verimliliğinin başka deyişle kuru madde miktarının tahmin edilmesinde bu iki değişken kullanılarak oluşturulacak regresyon modeli ile kuru madde miktarı tahmin 
edilebilecektir. Klorofil $a$ analizi laboratuvar imkanları ve çalışması gerektirir. Ancak optik yoğunluk bir spektrofotometre ile kolayca okunabilen, kültürdeki hücre yoğunluğu hakkında fikir veren bir değerdir. Kültürün büyüme evresi ya da biyomas verimliliği tahmininde kullanımında kolaylık sağlayacaktır.

\section{KAYNAKLAR}

Acièn Fernàndez, G. F., Garcia Camacho, F., Sanchez Perez, J. A., Fernandez Sevilla, J. M. \& Molina Grima, E. (1997). A model for light distribution and avarage solar irradiance inside outdoor tubular photobioreactors fort he microalgal mass culture. Biotechnology and Bioengineering, vol. 55, no. 5, September 5. John Wiley and Sons, Inc.

Acièn Fernàndez, G. F., Garcia Camacho, F., Sanchez Perez, J. A., Fernandez Sevilla, J. M. \& Molina Grima, E. (1998). Modeling of Biomass productivity in tubular photobioreactors for microalgal cultures: effects of dilution rate, tube diameter, and solar irradiance. Biotechnology and Bioengineering, vol. 58. No. 6, June 20. John Wiley and Sons, Inc.

Acièn Fernàndez, G. F., Sanchez Perez, J. A., Fernandez Sevilla, J. M., Garcia Camacho, F. \& Molina Grima, E. (2000). Modeling of eicosapentaenoic acid (EPA) production from Phaeodactylum tricornutum cultures in tubular photobioreactors. Effects of dilution rate, tube diameter, and solar irradiance. Biotechnology and Bioengineering, vol. 68. No. 2, April 20. John Wiley and Sons, Inc.

Acièn Fernàndez, G.F., Hall, D.O., Cañizares Guerrero, E., Krishna Rao, K. \& Molina Grima, E. (2003). Outdoor production of Phaeodactylum Tricornutum biomass in a helical reactor. Journall of Biotechnology, 103 , 137-152.

Ak, B. (2013). Azot eksikliğine bağlı stresin, fotobiyoreaktörde kültüre alınan Phaeodactylum Tricornutum'un (bacillariophyceae) lipid miktarına etkisi. Çukurova Üniversitesi, Fen Bilimleri Enstitüsü, Su Ürünleri Fakültesi, Yüksek Lisans Tezi, Adana.

Ak, B., Işık, O., Uslu, L. \& Azgın, C. (2015) The effect of stress due to nitrogen limitation on lipid content of phaeodactylum tricornutum (bohlin) cultured outdoor in photobioreactor. Turkish Journal of Fisheries and Aquatic Sciences, 15, 647-652.

Becker, E.W. (1994). Microalgae biotechnology and microbiology. Cambridge Univerity Press, Cambridge.

Boussiba, S., Fan, L. \& Vonshak, A. (1992). Enchancement and determination of astaxanthin accumulation in green alga H.pluvialis. Methods In Enzymology, 213, 386-391.

Daşdağ, M.M., Çelik, M.Y., Satıcı, Ö., Akkuş, Z. \& Çelik, H.C. (2006). Hangi tür araştırmalarda path analizi kullanılmalıdır? IX Ulusal Biyoistatistik Kongresi, 5-9 Eylül 2006, Zonguldak.

Düzgüneş, O., Eliçin, A. \& Akman, N. (1976). Hayvan 1slahı. Ankara Üniversitesi, Ziraat Fakültesi Yayınları: 98, Ders Kitabı: 3, Ankara.

Fajardo, A. R., Cerdan, L. E., Medina, A.R, Acién Fernández , F. G., González Moreno, P. A. \& Grima, E. M. (2007). Lipid extraction from the microalga Phaeodactylum tricornutum. Eur. J. Lipid Sci. and Tec., 109 (2), 120-126.

Griffiths, M.J., Garcin, C., Van Hille, R.P. \& Harrison, S.T. (2011). Interference by pigment in the estimation of microalgal biomass concentration by optical density. J Microbiol Methods, $85,119-123$.

Kaşıkçı, D. (2000). Path katsayısı, kısmi regresyon katsayısı ve korelasyon katsayılarının karşılaştırmalı olarak incelenmesi. Yüksek Lisans Tezi, Süleyman Demirel Üniversitesi, Fen Bilimleri Enstitüsü, Isparta.

Kilham, S.S., Kreeger, D.A., Goulden, C.A. \& Lynn, S.G. (1997). Effects of nutrient limitation on biochemical constituents of Ankistrodesmus falcatus. Freshwater Biology, 38, 591-596.

Li, C.C. (1975). Path analysis - a primer. The Boxwood Press, Pacific Grove, California, USA.

Liang, Y. H., Beardall, J. \& Heraud, P. (2006). Effects of nitrogen source and UV radiation on the growth, chlorophyll flourescence and fatty acid composition of Phaeodactylum tricornutum 
and Chaetoceros muelleri (Bacillariophyceae). Journal of Photochemistry and Photobiology B:Biology, 82, 161-172.

Madenci, P. (2012). Farklı 1şık şiddetlerinin Phaeodactylum tricornutum (Bohlin, 1897) ve Dunaliella Tertiolecta (Butcher, 1959) türlerinin büyümesi üzerine etkileri. Ege Üniversitesi, Fen Bilimleri Enstitüsü, Yüksek Lisans Tezi, İzmir.

Mendeş, M., Karabayır, A. \& Pala, A. (2005). Path analysis of the relationships between various body measures and live weight of american bronze turkeys under three different lighting programs. Tarım Bilimleri Dergisi, 11(2), 184-188.

Oktay, E., Akıncı, M.M. \& Karaaslan, A. (2012). Yol analizi yardımıyla dersler arasındaki etkileşimin araştırılması: Atatürk Üniversitesi İktisadi ve İdari Bilimler Fakültesi İşletme Bölümünde okutulan dersler üzerine bir uygulama. Atatürk Üniversitesi, Íktisadi ve İdari Bilimler Dergisi, 26, 67-83.

Öztürk, İ. (2014). Hayvansal üretim verilerinde çoklu bağlantı probleminin yanlı regresyon yöntemi ile çözümlenmesi. KSÜ Doğa Bilimleri Dergisi, 17(3), 1-12.

Parsons, T.R. \& Strickland, J.D.H. (1963). Discussion of spectrophotometric determination of marine plant pigments with revised equations for ascertaining chlorophylss and carotenoids. Journal of Marine Research, 21 (3), 115-163.

Pruvost, J., Van Vooren, G., Cogne, G. \& Legrand, J. (2009). Investigation of biomass and lipids production with Neochloris oleoabundans in photobioreactor. Bioresource Technology, 100, 5988-5995.

Richmond, A. (2004). Handbook of Microalgae Culture: Biotechnology and Applied Phycology. In: Basic Culturing Techniques (Eds; Lee Yuan-Kun ve Shen Hui) Oxford: Blackwell Science, pp:40-56.

Sıralı, R. \& Kayaalp, G.T. (1995). Trakya Bölgesi arılarının bal verim özelliği ve bu özelliği etkileyen bazı faktörlerin path analizi yöntemi ile saptanması. Harran Üniversitesi, Ziraat Fakültesi Dergisi, 1 (2), 211-217.

Siron, R., Giusti, G. \& Berland, B. (1989). Changes in the fatty acid composition of Phaeodactylum tricornutum and Dunaliella Tertiolecta during growth and under phosphorus deficiency. Marine Ecology Progress Series, 55, 95-100.

Slade, R. \& Bauen A. (2013). Micro-algae cultivation for biofuels: Cost, energy balance, environmental impacts and future prospects. Biomass and Bioenergy, 53, 29- 38.

Sukenik, A. \& Wahnon, R. (1991). Biochemical quality of marine unicellular algae with special emphasis on lipid composition. I. Isochrysis galbana. Aquaculture, 97(1), 61-72.

Ward, O. P. \& Yongmanitchai, W. (1991). Growth of and omega-3 fatty acid production by Phaeodactylum tricornutum under different culture conditions. Appl. Environ. Microbiol., 57, 2419-425.

Webster, A. (1995). Applide statistics for business and economics. Page: 683-684.

Wright, S. (1921). Correlation and causation. Journal of Agricultural Research, 20 (7), 557-585.

Xin, L., Hong-ying, H., Ke, G. \& Ying-xue, S. (2010). Effects of different nitrogen and phosphorus concentrations on the growth, nutrient uptake, and lipid accumulation of a freshwater microalgae Scenedesmus sp. Bioresour. Technol., 101, 5494- 5500. 